\title{
Nonarteritic anterior ischemic optic neuropathy: cause, effect, and management
}

Shauna Berry'

Weijie V Lin²

Ama Sadaka'

Andrew G Lee ${ }^{1-7}$

'Department of Ophthalmology, Blanton Eye Institute, Houston Methodist Hospital, Houston, TX, USA; '2Department of Ophthalmology, Baylor College of Medicine,

Houston, TX, USA; ${ }^{3}$ Department of Ophthalmology and Visual Sciences, University of Texas Medical Branch (UTMB), Galveston, TX, USA;

${ }^{4}$ Department of Ophthalmology, ${ }^{5}$ Department of Neurology,

${ }^{6}$ Department of Neurosurgery, Weill Cornell Medicine, Houston, TX, USA; ${ }^{7}$ Department of Ophthalmology, The University of Texas MD Anderson Cancer Center, Houston, TX, USA
Correspondence: Andrew G Lee Department of Ophthalmology, Blanton Eye Institute, Houston Methodist Hospital, 6560 Fannin Street, Suite 450, Houston, TX 77030, USA

$\mathrm{Tel}+\mathrm{I} 71344 \mid 8843$

Fax +I 7137931636

Email aglee@houstonmethodist.org
This article was published in the following Dove Press journal:

Eye and Brain

27 September 2017

Number of times this article has been viewed
Abstract: Nonarteritic anterior ischemic optic neuropathy (NAION) is the most common form of ischemic optic neuropathy and the second most common optic neuropathy. Patients are generally over the age of 50 years with vasculopathic risk factors (eg, diabetes mellitus, hypertension, and obstructive sleep apnea). The exact mechanism of NAION is not fully understood. In addition, several treatment options have been proposed. This article summarizes the current literature on the diagnosis, treatment, and management of NAION.

Keywords: anterior ischemic optic neuropathy, nonarteritic anterior ischemic optic neuropathy, ischemic optic neuropathy

\section{Introduction}

Nonarteritic anterior ischemic optic neuropathy (NAION) is the second most common optic neuropathy after glaucoma caused by infarction of the short posterior ciliary arteries that supply the anterior portion of the optic nerve head. This leads to axonal edema and a compartment syndrome in an already crowded optic disc causing vision loss. ${ }^{1}$ Annually, there are $\sim 6,000$ new cases in the United States. ${ }^{1}$ Significant research on pathophysiology, prevention, and treatment has been performed and will be discussed in this review, but remains limited.

\section{Clinical presentation and pathogenesis}

NAION typically presents with acute unilateral painless vision loss accompanied by sector or diffuse optic nerve edema. ${ }^{2}$ It occurs more frequently in the Caucasian population and there is no gender predilection. ${ }^{1,2}$ It generally affects people over 50 years of age, with a mean onset between 57 and 65 years of age. However, it has also been reported in patients $<40$ years old both with and without vasculopathic risk factors (ie, NAION of the young [NAIONY]). ${ }^{3}$ Visual field (VF) defects following a nerve fiber layer distribution are typical VF findings, with inferior altitudinal and arcuate defects being the most common. ${ }^{1,2,4}$ Patients may describe the vision loss as a "dim or blur", especially in the area of the field loss. ${ }^{1}$ Hayreh et al noted that vision loss was often reported upon awakening, and some authors believe that the etiology for NAION is nocturnal hypotension. ${ }^{5}$ Vision loss from NAION is variable but is typically less severe than the loss from arteritic anterior ischemic optic neuropathy (A-AION). Hayreh et al observed the initial visual acuity (VA) to be $20 / 30$ or better in $49 \%$ of cases of NAION. ${ }^{5}$ An ipsilateral relative afferent pupillary defect will be present in unilateral or bilateral but asymmetric cases. Sector or diffuse disc edema in the acute phase of the disease is 
essential for clinical diagnosis. The disc edema may or may not be accompanied by peripapillary hemorrhages. ${ }^{3}$ Macular edema and exudates are less common.

Although the exact pathogenesis of NAION remains unproven, it appears to be a multifactorial disease. ${ }^{4}$ It is presumed to be due to a transient disruption in the circulation of the optic nerve head leading to hypoperfusion and ischemia. The exact cause of this transient disturbance remains unclear but several hypotheses have been proposed including generalized hypoperfusion, nocturnal hypotension, local autoregulation failure, vasospasm, venous occlusion, and thrombosis. In addition, patients with NAION typically have a small cup-to-disc ratio as a predisposing factor, and this "crowded optic disc head" has been referred to as the "structural disc at risk" for NAION. Theoretically, when localized swelling occurs in a fixed space anterior to the rigid lamina cribosa, the capillaries could become more easily compressed and secondary ischemia may result. ${ }^{1,2}$ Recent studies of the optic nerve head utilizing optical coherence tomography (OCT) have demonstrated thicker prelaminar tissue in NAION patients. ${ }^{7}$ Systemic diseases that may cause decreased perfusion to the optic nerve head secondary to microvascular compromise might increase the patient's risk of NAION. These include hypertension, diabetes, and hypercholesterolemia. Other risk factors noted in the literature are nocturnal hypotension, smoking, obstructive sleep apnea, anemia, hypercoagulable states, disc drusen, ocular and nonocular surgery, and migraines. The use of vasoactive medications may be an additional risk factor for NAION. Phosphodiesterase type-5 inhibitors (PDE-5i) have recently been implicated in NAION; however, there is still much debate over this topic. A recent observational study reported an increase of 2.21 in the odds ratio of an NAION in patients using PDE-5i up to 30 days prior ${ }^{2,8}$ to the event. Amiodarone has also been associated with NAION. ${ }^{9}$

\section{Prognosis}

Although a progressive form of NAION has been reported, the course of NAION typically stabilizes within 2-3 months. ${ }^{1}$ The visual prognosis is generally guarded; however, the acuity may improve by up to three lines in $43 \%$ of patients. ${ }^{1,10}$ The VF defects are less likely to improve. There is $<5 \%$ chance of recurrence in the same eye. ${ }^{1,11}$ The initial disc edema usually resolves, and sector or diffuse atrophy ensues typically within the next 6-11 weeks. $^{1}$

Work-up for other etiologies of optic disc edema, however, should be considered if the edema persists beyond this time frame (eg, compressive lesion, optic nerve sheath meningioma, and infectious, infiltrative, or inflammatory optic neuropathies). There is up to a $15 \%$ chance of fellow eye involvement at 5 years. ${ }^{14,15}$ The VA and VF defect in a patient with prior NAION cannot directly predict the prognosis of visual impairment if there is second eye involvement. ${ }^{12,13}$ This presentation of optic disc edema in one eye and optic atrophy in the fellow eye can produce a "pseudo-Foster Kennedy" syndrome. The key in differentiating between "pseudo-Foster Kennedy" and a true Foster Kennedy is the history of abrupt vision loss in the affected eye with optic disc edema (acute NAION) and a history of prior visual loss in the contralateral eye with optic atrophy (old NAION). In the true Foster Kennedy syndrome, there is no abrupt vision loss as the pale disc is from a compressive etiology and the fellow edematous disc is secondary to papilledema from increased intracranial pressure. ${ }^{1}$

\section{Management and treatment}

NAION is primarily a clinical diagnosis. The most important initial step in management is to exclude giant cell arteritis (ie, A-AION). The presence of pallid edema on exam and symptoms including pain, jaw claudication, scalp tenderness, fever, and malaise should raise suspicion for A-AION.

Patients presenting with typical features generally do not need neuroimaging or additional laboratory testing other than erythrocyte sedimentation rate (ESR), C-reactive protein (CRP), or platelet count. ${ }^{16}$ Other causes of optic neuropathies should be considered in the presence of atypical features. Table 1 summarizes some of the atypical features. Some patients may require cranial and orbital magnetic resonance imaging (MRI; eg, progressive NAION) and, rarely, head and neck MR-angiogram (MRA) or computed tomography angiography (CTA) may be considered in patients presenting with unilateral head or neck pain to exclude a carotid dissection. ${ }^{1-3,17,18}$

Table I Atypical features for NAION

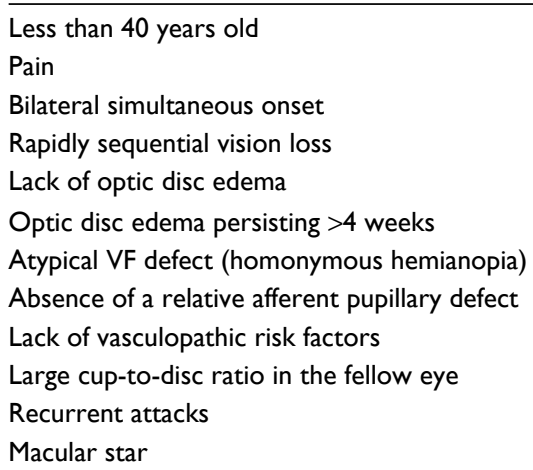

Abbreviations: VF, visual field; NAION, nonarteritic anterior ischemic optic neuropathy. 
A thorough history, including medications (eg, PDE-5i, amiodarone), past medical history (eg, vasculopathic risk factors), recent surgical history, and social history (eg, smoking), is key. Patients should be evaluated by their primary care physicians for modifiable risk factors including hypertension, hyperlipidemia, diabetes mellitus, and obstructive sleep apnea.

A carotid workup is generally not indicated in typical NAION but can be considered in the presence of ocular ischemic syndrome, retinal emboli, or transient neurological deficits..$^{19}$ OCT can be used to monitor the disease course for long term with the assessment of edema and optic atrophy, but NAION remains a clinical diagnosis and there are no diagnostic OCT features of NAION. Some recent studies have demonstrated the use of OCT in the assessment, diagnosis, and management of NAION. ${ }^{6}{ }^{20}$ Findings include increased peripapillary choroidal thickness associated with optic disc edema and subretinal fluid on spectral domain OCT (SD-OCT) and macular ganglion cell inner plexiform layer thinning associated with $\mathrm{VF}$ defect in frequency domain OCT (FD-OCT). ${ }^{6}{ }^{21}$ Another study found that NAION affected neither the cup-to-disc ratio nor alpha or beta zone of parapapillary atrophy. ${ }^{22}$ Ganglion cell layer plus inner plexiform layer (GCL+IPL) thinning has been shown to be better than retinal nerve fiber layer (RNFL) thinning in indicating early structural loss in NAION. ${ }^{23}$ The application of OCT-angiography (OCT-A) in NAION is also being studied. OCT-A is a useful noninvasive technique in depicting ocular perfusion in comparison to fluorescein angiography. It can also be used in pregnant patients and those allergic to fluorescein. A case study by Higashiyama et al demonstrated areas of decreased retinal perfusion on OCT-A consistent with the RNFL and gangion cell complex loss in NAION. ${ }^{24}$ Another study by Sharma et al examined the microvascular perfusion during the acute and follow-up stages of NAION. OCT-A demonstrated segmental and global reduction of the peripapillary flow in the acute phase with subsequent spontaneous partial recovery consistent with visual recovery and the natural course of NAION. Furthermore, the temporal sector of the nerve head not only demonstrated the highest flow density in healthy controls, but also demonstrated the most damage in eyes with NAION. ${ }^{25}$ They also found that there was no disruption of the microvasculature in the healthy unaffected eye. The authors proposed that this could be subsequent to the temporal watershed zone discussed by Hayreh $^{26}$ which correlates with the predominance of nasal field defects in NAION.
To date, no definitive high-grade evidence for an effective treatment of NAION exists (Table 2). The highest level of evidence comes from the Ischemic Optic Neuropathy Decompression Trial (IONDT). ${ }^{1,2,10}$ This was a prospective, randomized trial that assessed optic nerve sheath fenestration as a treatment for NAION. It was the only randomized controlled trial for NAION. It was based upon the theory that an optic nerve sheath fenestration could reduce the compartment syndrome effect. ${ }^{1}$ However, the study concluded that optic nerve sheath fenestration was not an effective intervention and may actually have a harmful effect. ${ }^{10}$

Other treatment options explored include medical therapies such as aspirin, steroids, and neuroprotective agents. Aspirin has been studied as a primary treatment for NAION as well as a preventive measure of fellow eye involvement. A retrospective case-controlled study showed no improvement in the final visual outcome in those treated with aspirin before, during, and following NAION compared with those who did not receive any aspirin. ${ }^{27}$ The majority of the retrospective and case-control studies examined aspirin for its use in preventing NAION in the fellow eye. ${ }^{12,14,27,28}$ Data from the retrospective studies are controversial. The most convincing data come from the follow-up to the Ischemic Optic Neuropathy Decompression Trial (IONDT) and a large retrospective review by Beck et al. The IONDT follow-up suggested that aspirin did not influence the rate of recurrence. ${ }^{15}$ The large retrospective study of 431 patients with NAION by Beck et al suggests a possible short-term benefit of aspirin (cumulative probability of $7 \%$ in aspirin group and $15 \%$ in non-aspirin group at 2 years) but lacks a long-term benefit in reducing the risk of NAION in the fellow eye (17\% aspirin group vs $20 \%$ untreated group at 5 years).${ }^{14}$ Despite sufficient evidence of long-term benefit of aspirin, many still recommend it following the initial NAION because of the vasculopathic risk factors associated with NAION. This becomes more important when considering the data on increased risk of ischemic stroke in patients with NAION. A recent retrospective study found a 3.35 times increased risk of developing an ischemic stroke in patients with NAION compared to patients with similar comorbidities but without NAION. ${ }^{29}$ However, like much of the data, there is conflicting opinions in this association..$^{29,30}$

Steroids, administered systemically, periocularly, or intraocularly, have been proposed as treatment modalities with the earliest report dating back to the late $1960 \mathrm{~s} \cdot .^{1-3,31,32}$ The initial study demonstrated improvement in 11 of $13(85 \%)$ patients treated with $60 \mathrm{mg}$ /day oral prednisone compared to 5 of 11 (45\%) untreated patients. The authors postulated that steroids 
Table 2 Summary of some of the studies that explored treatment of NAION

\begin{tabular}{|c|c|c|c|}
\hline Treatment & $\begin{array}{l}\text { Hypothesized } \\
\text { mechanism of action }\end{array}$ & $\begin{array}{l}\text { Type of study (level of } \\
\text { evidence) }\end{array}$ & Outcome \\
\hline \multicolumn{4}{|l|}{ Surgical } \\
\hline ONSD & $\begin{array}{l}\text { To resolve the } \\
\text { "compartment syndrome" }\end{array}$ & $\begin{array}{l}\text { Masked, prospective, } \\
\text { randomized (I) }\end{array}$ & $\begin{array}{l}32.6 \% \text { surgery patients improved compared to } 42.7 \% \text { of } \\
\text { observation group } 12,20\end{array}$ \\
\hline RON & $\begin{array}{l}\text { To resolve the } \\
\text { "compartment syndrome" }\end{array}$ & Randomized, control (II) & $\begin{array}{l}75 \% \text { of eight treated eyes improved with } \mathrm{RON} \text {, one eye } \\
\text { developed a choroidal neovascular membrane. } 25 \% \text { of eight } \\
\text { untreated eyes improved }{ }^{18}\end{array}$ \\
\hline \multicolumn{4}{|l|}{ Systemic } \\
\hline Systemic corticosteroids & Decreased disc swelling & $\begin{array}{l}\text { Nonrandomized } \\
\text { controlled study (III) }\end{array}$ & $\begin{array}{l}\text { VA improved in } 69.8 \% \text { of } 236 \text { treated patients and in } 40.5 \% \\
\text { of } 30 \text { I untreated. VF improved in } 40.1 \% \text { of treated patients } \\
\text { and in } 24.5 \% \text { of untreated }\end{array}$ \\
\hline $\begin{array}{l}\text { Combined systemic } \\
\text { corticosteroids and } \\
\text { erythropoietin }\end{array}$ & $\begin{array}{l}\text { Decrease disc swelling } \\
\text { and neuroprotection }\end{array}$ & $\begin{array}{l}\text { Prospective } \\
\text { interventional case series }\end{array}$ & $\begin{array}{l}\text { No benefit in combined corticosteroids and erythropoietin } \\
\text { versus systemic corticosteroids alone versus control in } \\
\text { final VA }\end{array}$ \\
\hline Oral levodopa & Neuroprotection & $\begin{array}{l}\text { Retrospective, } \\
\text { nonrandomized }\end{array}$ & $\begin{array}{l}76.9 \% \text { of } 18 \text { treated improved } \\
30 \% \text { of } 19 \text { untreated improved }\end{array}$ \\
\hline Aspirin & Improves blood flow & Retrospective $^{\mathrm{a}}$ & $\begin{array}{l}\text { IONDT showed no association between regular aspirin use } \\
\text { and the incidence of fellow eye NAION }\end{array}$ \\
\hline \multicolumn{4}{|l|}{ Topical } \\
\hline Topical brimonidine & Neuroprotection & $\begin{array}{l}\text { Multicenter, randomized, } \\
\text { clinical trial (II) } \\
\text { Retrospective (III) }\end{array}$ & $\begin{array}{l}\text { No VF or VA improvements. Both trials NPION and } \\
\text { BRAION discontinued due to recruitment difficulties } \\
\text { Treated patients had worse outcomes in all visual } \\
\text { parameters }{ }^{14}\end{array}$ \\
\hline \multicolumn{4}{|l|}{ Intravitreal } \\
\hline Intravitreal steroids & Decreased disc edema & Case controlled (III) & VA improved in 4 treated and 6 untreated $^{18}$ \\
\hline Intravitreal erythropoietin & Neuroprotection & Prospective case series & $\begin{array}{l}61.2 \% \text { VA improved with treatment, but no VF } \\
\text { improvement }^{19}\end{array}$ \\
\hline Intravitreal anti-VEGF & $\begin{array}{l}\text { Reduced vasogenic disc } \\
\text { swelling }\end{array}$ & $\begin{array}{l}\text { Various case reports, } \\
\text { case series (IV) }\end{array}$ & $\begin{array}{l}\text { A faster resolution of disc edema and improved visual } \\
\text { outcome were documented }^{15}\end{array}$ \\
\hline $\begin{array}{l}\text { Intravitreal injection of QPI- } \\
\text { I007 (siRNA) }\end{array}$ & Neuroprotection & $\begin{array}{l}\text { Clinical trial is still } \\
\text { recruiting patients }\end{array}$ & \\
\hline
\end{tabular}

Note: ${ }^{a}$ The IONDT was a prospective trial to evaluate ONSD in the management of NAION. Aspirin data were observational only.

Abbreviations: IONDT, Ischemic Optic Neuropathy Decompression Trial; NAION, nonarteritic anterior ischemic optic neuropathy; ONSD, optic nerve sheath decompression; RON, radial optic neurotomy; siRNA, small interfering ribonucleic acid; VA, visual acuity; VEGF, vascular endothelial growth factor; VF, visual field.

would decrease the capillary permeability, subsequently accelerating the resolution of the disc edema and reducing the compressions of capillaries on the optic nerve head and therefore improving blood flow to ischemic axons. ${ }^{31,33}$ Hayreh and Zimmerman conducted a large nonrandomized study in which patients could elect to be treated with oral prednisone $80 \mathrm{mg} /$ day for 14 days followed by a 2-month taper. The authors observed improvement of visual function in those treated compared to the untreated controls. However, the nonrandomized and unmasked nature of the study, the older age and higher vasculopathic comorbidities of their untreated patients, and the large steroid dose that carries systemic side effects with it weaken the findings. ${ }^{34}$ Evidence for intravitreal administration of steroids remains controversial. ${ }^{35}$

Additional treatment efforts aimed at neuroprotection with agents such as intravitreal erythropoietin, oral levodopa, diphenylhydantoin, topical brimonidine tartrate, hyperbaric oxygen, and transcorneal electrical stimulation have been explored. ${ }^{36-45}$ However, these studies are limited by their small number of patients and absence of control. Emerging on the forefront of neuroprotective efforts is intravitreal small interfering ribonucleic acid (siRNA) injections. siRNA prevents apoptosis by inhibiting the expression of caspase-2. This randomized, double-masked study is still in the patient recruitment phase with no data available yet. ${ }^{46}$

\section{Conclusion}

NAION remains a common disease with devastating consequences for patients, unclear pathophysiology, and contradictory data regarding fellow eye involvement and treatment.

In our experience, if you are considering the diagnosis of NAION in a patient presenting with acute vision loss and optic disc edema, we recommend that you think of the following: 1) look for atypical features that would make you 
consider diagnoses other than NAION (Table 1); 2) ask about vasculopathic risk factors and always look for other medical problems that can be associated with the disc edema such as inflammatory and neoplastic diseases; 3 ) if the patient is in the appropriate age group, has vasculopathic risk factors, has a disc at risk in the fellow eye, and has no atypical features, then you can make a diagnoses of NAION, but continue to monitor the patient. Once the diagnoses of NAION is made, we recommend counseling the patient about better control of their vasculopathic risk factors including referral to a primary care physician, smoking cessation, weight loss, and exercise. We also recommend an aspirin a day, if there is no contraindication, to all our patients despite the lack of level I evidence to prove benefit. The future holds promise with neuroprotective and inflammatory modulating agents.

\section{Disclosure}

The authors report no conflicts of interest in this work.

\section{References}

1. Miller NR, Arnold AC. Current concepts in the diagnosis, pathogenesis and management of nonarteritic anterior ischaemic optic neuropathy Eye (Lond). 2015;29(1):65-79.

2. Barros AE, Amram AL, Derham AM, Smith SV, Lee AG. Management of ischemic optic neuropathies. Expert Rev Ophthalmol. 2017;12(2):99-109.

3. Lee AG, Brazis PW. Clinical Pathways in Neuro-Ophthalmology: An Evidence-Based Approach. Stuttgart, Germany: Thieme; 2003.

4. Nazari H, Berry S, Sadaka A, Lee AG. Managing NAION. Specialist. 2017;15:201715

5. Hayreh SS, Zimmerman MB, Podhajsky P, Alward WL. Nonarteritic anterior ischemic optic neuropathy: role of nocturnal arterial hypotension. Arch Ophthalmol. 1997;115(7):942-945.

6. Han S, Jung JJ, Kim US. Differences between non-arteritic anterior ischemic optic neuropathy and open angle glaucoma with altitudinal visual field defect. Korean J Ophthalmol. 2015;29(6):418-423.

7. Moghimi S, Afzali M, Akbari M, et al. Crowded optic nerve head evaluation with optical coherence tomography in anterior ischemic optic neuropathy. Eye (Lond). 2017;31(8):1191-1198.

8. Campbell UB, Walker AM, Gaffney M, et al. Acute nonarteritic anterior ischemic optic neuropathy and exposure to phosphodiesterase type 5 inhibitors. J Sex Med. 2015;12(1):139-151.

9. Passman RS, Bennett CL, Purpura JM, et al. Amiodarone-associated optic neuropathy: a critical review. Am J Med. 2012;125(5):447-453.

10. Optic nerve decompression surgery for nonarteritic anterior ischemic optic neuropathy (NAION) is not effective and may be harmful. The Ischemic Optic Neuropathy Decompression Trial Research Group. JAMA. 1995;273(8):625-632.

11. Hayreh SS, Podhajsky PA, Zimmerman B. Ipsilateral recurrence of nonarteritic anterior ischemic optic neuropathy. Am J Ophthalmol. 2001;132(5):734-742.

12. Kupersmith MJ, Frohman L, Sanderson M, et al. Aspirin reduces the incidence of second eye NAION: a retrospective study. J Neuroophthalmol. 1997;17(4):250-253.

13. Hayreh SS, Zimmerman MB. Bilateral nonarteritic anterior ischemic optic neuropathy: comparison of visual outcome in the two eyes. J Neuroophthalmol. 2013;33(4):338-343.
14. Beck RW, Hayreh SS, Podhajsky PA, Tan ES, Moke PS. Aspirin therapy in nonarteritic anterior ischemic optic neuropathy. Am J Ophthalmol. 1997;123(2):212-217.

15. Newman NJ, Scherer R, Langenberg P, et al. The fellow eye in NAION: report from the ischemic optic neuropathy decompression trial follow-up study. Am J Ophthalmol. 2002;134(3):317-328.

16. Arnold AC, Hepler RS, Hamilton DR, Lufkin RB. Magnetic resonance imaging of the brain in nonarteritic ischemic optic neuropathy. J Neuroophthalmol. 1995;15(3):158-160.

17. Biousse V, Schaison M, Touboul PJ, D'Anglejan-Chatillon J, Bousser MG. Ischemic optic neuropathy associated with internal carotid artery dissection. Arch Neurol. 1998;55(5):715-719.

18. Biousse V, Touboul PJ, D’Anglejan-Chatillon J, Levy C, Schaison M, Bousser MG. Ophthalmologic manifestations of internal carotid artery dissection. Am J Ophthalmol. 1998;126(4):565-577.

19. Horton JC. Emnibolic cilioretinal artery occlusion with atherosclerosis of the ipsilateral carotid artery. Retina. 1995;15(5):441-444.

20. Balogh Z, Kasza M, Vardai J, et al. Analysis of optic disc damage by optical coherence tomography in terms of therapy in non-arteritic anterior ischemic optic neuropathy. Int J Ophthalmol. 2016;9(9):1352-1354.

21. Yu C, Ho JK, Liao YJ. Subretinal fluid is common in experimental non-arteritic anterior ischemic optic neuropathy. Eye (Lond). 2014;28(12):1494-1501.

22. Jonas JB, Hayreh SS, Tao Y, Papastathopoulos KI, Rensch F. Optic nerve head change in non-arteritic anterior ischemic optic neuropathy and its influence on visual outcome. PLoS One. 2012;7(5):e37499.

23. Kupersmith MJ, Garvin MK, Wang JK, Durbin M, Kardon R. Retinal ganglion cell layer thinning within one month of presentation for optic neuritis. Mult Scler. 2016;22(5):641-648.

24. Higashiyama T, Ichiyama Y, Muraki S, Nishida Y, Ohji M. Optical coherence tomography angiography in a patient with optic atrophy after non-arteritic anterior ischaemic optic neuropathy. Neuroophthalmology. 2016;40(3):146-149.

25. Sharma S, Ang M, Najjar RP, et al. Optical coherence tomography angiography in acute non-arteritic anterior ischaemic optic neuropathy. Br J Ophthalmol. 2017;101(8):1045-1051.

26. Hayreh SS. Posterior ciliary artery circulation in health and disease: the Weisenfeld lecture. Invest Ophthalmol Vis Sci. 2004;45(3):749-757;748.

27. Botelho PJ, Johnson LN, Arnold AC. The effect of aspirin on the visual outcome of nonarteritic anterior ischemic optic neuropathy. $\mathrm{Am} \mathrm{JOph-}$ thalmol. 1996;121(4):450-451.

28. Salomon O, Huna-Baron R, Steinberg DM, Kurtz S, Seligsohn U. Role of aspirin in reducing the frequency of second eye involvement in patients with non-arteritic anterior ischaemic optic neuropathy. Eye (Lond). 1999;13(Pt 3a):357-359.

29. Lee YC, Wang JH, Huang TL, Tsai RK. Increased risk of stroke in patients with nonarteritic anterior ischemic optic neuropathy: a nationwide retrospective cohort study. Am JOphthalmol. 2016;170:183-189.

30. Hayreh SS. Increased risk of stroke in patients with nonarteritic anterior ischemic optic neuropathy: a nationwide retrospective cohort study. Am J Ophthalmol. 2017;175:213-214.

31. Lee AG, Biousse V. Should steroids be offered to patients with nonarteritic anterior ischemic optic neuropathy? J Neuroophthalmol. 2010;30(2):193-198.

32. Foulds WS. Visual disturbances in systemic disorders. Optic neuropathy and systemic disease. Trans Ophthalmol Soc U K. 1970;89:125-146.

33. Atkins EJ, Bruce BB, Newman NJ, Biousse V. Treatment of nonarteritic anterior ischemic optic neuropathy. Surv Ophthalmol. 2010;55(1):47-63.

34. Hayreh SS, Zimmerman MB. Non-arteritic anterior ischemic optic neuropathy: role of systemic corticosteroid therapy. Graefes Arch Clin Exp Ophthalmol. 2008;246(7):1029-1046.

35. Kaderli B, Avci R, Yucel A, Guler K, Gelisken O. Intravitreal triamcinolone improves recovery of visual acuity in nonarteritic anterior ischemic optic neuropathy. J Neuroophthalmol. 2007;27(3):164-168. 
36. Foroozan R. New Treatments for nonarteritic anterior ischemic optic neuropathy. Neurol Clin. 2017;35(1):1-15.

37. Tao Y, Chen T, Liu B, et al. The transcorneal electrical stimulation as a novel therapeutic strategy against retinal and optic neuropathy: a review of experimental and clinical trials. Int J Ophthalmol. 2016;9(6): 914-919.

38. Chuman H. [Nonarteritic ischemic optic neuropathy animal model and its treatment applications]. Nippon Ganka Gakkai Zasshi. 2014;118(4): 331-361.

39. Rootman DB, Gill HS, Margolin EA. Intravitreal bevacizumab for the treatment of nonarteritic anterior ischemic optic neuropathy: a prospective trial. Eye (Lond). 2013;27(4):538-544.

40. Prescott CR, Sklar CA, Lesser RL, Adelman RA. Is intravitreal bevacizumab an effective treatment option for nonarteritic anterior ischemic optic neuropathy? J Neuroophthalmol. 2012;32(1): $51-53$.

41. Modarres M, Falavarjani KG, Nazari H, et al. Intravitreal erythropoietin injection for the treatment of non-arteritic anterior ischaemic optic neuropathy. Br J Ophthalmol. 2011;95(7):992-995.
42. Wilhelm B, Ludtke H, Wilhelm H, Group BS. Efficacy and tolerability of $0.2 \%$ brimonidine tartrate for the treatment of acute non-arteritic anterior ischemic optic neuropathy (NAION): a 3-month, doublemasked, randomised, placebo-controlled trial. Graefes Arch Clin Exp Ophthalmol. 2006;244(5):551-558.

43. Johnson LN, Guy ME, Krohel GB, Madsen RW. Levodopa may improve vision loss in recent-onset, nonarteritic anterior ischemic optic neuropathy. Ophthalmology. 2000;107(3):521-526.

44. Johnson LN, Gould TJ, Krohel GB. Effect of levodopa and carbidopa on recovery of visual function in patients with nonarteritic anterior ischemic optic neuropathy of longer than six months' duration. Am J Ophthalmol. 1996;121(1):77-83.

45. Arnold AC, Hepler RS, Lieber M, Alexander JM. Hyperbaric oxygen therapy for nonarteritic anterior ischemic optic neuropathy. Am J Ophthalmol. 1996;122(4):535-541.

46. Solano EC, Kornbrust DJ, Beaudry A, Foy JW, Schneider DJ, Thompson JD. Toxicological and pharmacokinetic properties of QPI-1007, a chemically modified synthetic siRNA targeting caspase 2 mRNA, following intravitreal injection. Nucleic Acid Ther. 2014;24(4):258-266.
Eye and Brain

\section{Publish your work in this journal}

Eye and Brain is an international, peer-reviewed, open access journal focusing on clinical and experimental research in the field of neuroophthalmology. All aspects of patient care are addressed within the journal as well as basic research. Papers covering original research, basic science, clinical and epidemiological studies, reviews and evaluations,

Submit your manuscript here: https://www.dovepress.com/eye-and-brain-journal
Dovepress

guidelines, expert opinion and commentary, case reports and extended reports are welcome. The manuscript management system is completely online and includes a very quick and fair peer-review system, which is all easy to use. Visit http://www.dovepress.com/testimonials.php to read real quotes from published authors. 